\title{
ANALISIS PENGARUH SUDU TERHADAP UNJUK KERJA TURBIN ANGIN ATAP RUMAH PADA KECEPATAN ANGIN RENDAH MENGGUNAKAN SIMULASI CFD
}

\author{
${ }^{(1)}$ Mujiburrahman, ${ }^{(2)}$ Heri Irawan \\ ${ }^{(1)(2)}$ Prodi Teknik Mesin Fakultas Teknik, Universitas Islam Kalimantan MAB \\ Jl. Adhiyaksa No. 2 Kayu Tangi, Banjarmasin \\ Email: mujiburrahman.4646@gmail.com, heri.irawan.up@gmail.com
}

\begin{abstract}
ABSTRAK
Turbin angin yang di aplikasikan pada puncak kemiringan atap bentuk memanjang sangat jarang di aplikasikan di indonesia mengingat potensi angin kemiringan atap rumah yang tergolong kecepatan angin rendah dan cendrung ber ubahubah arah. Sehingga perlu dikembangkan turbin angin atap rumah yang mampu memaksimalkan angin rendah. (Watson et, 2008), melihat permasalahan tersebut tentunya pemilihan jenis turbin, bentuk airfoil, dan jumlah blade sangat menentukan prestasi turbin angin atap rumah. Selain itu pertimbangan aerodinamika bentuk airfoil yang diinginkan tentunya memiliki self starting yang tinggi sehingga mampu menghasilkan daya keluaran, daya mekanik dan coefesien daya paling optimum. turbin angin jenis savonius memiliki kemampuan self-starting yang bagus, karena mampu memaksimalkan energi angin mendorong blade, sehingga hanya membutuhkan angin dengan kecepatan rendah untuk memutar rotor dari turbin angin ini. Selain itu, torsi yang dihasilkan blade turbin angin jenis savonius relatif tinggi (Sargolzei, 2007). Metode penelitian ini menggunakan percobaan eksprimen motion model, dengan variabel bebas faktor kecepatan angin $3 \mathrm{~m} / \mathrm{s}$. Jumlah blade 3,4, dan 5. Selanjutnya di simulasikan menggunakan Computational Fluid Dynamic, untuk melihat daya keluaran, daya mekanik dan coefesien daya paling optimum. Hasil pengujian turbin atap rumah blade 5 buah memiliki pengaruh paling besar terhadap daya mekanik sebesar $28.185 \mathrm{~W}$, dan koefisien daya $\mathrm{Cp}$, sebesar $0.58 \%$. Selanjutnya tertinggi kedua di hasilkan jumlah blade 4 buah memiliki pengaruh terhadap daya mekanik sebesar $27.96 \mathrm{~W}$, dan koefisien daya $\mathrm{Cp}$, sebesar $0.56 \%$. Sedangkan jumlah blade 3 buah memiliki pengaruh paling besar ketiga terhadap daya mekanik sebesar $27.86 \mathrm{~W}$, dan koefisien daya $\mathrm{Cp}$, sebesar $0.55 \%$.Dimensi model turbin angin atap rumah yang paling optimal dari ketiga model hasil simulasi desain dan perhitungan yaitu hasil simulasi desain no 3 . Turbin angin atap rumah jumlah blade 5 buah menghasilkan daya turbin maksimum sebesar, $28.185 \mathrm{~W}$, dan koefisien daya $\mathrm{Cp}$, sebesar $0.568 \%$. Menurut Betz limit, bahwa nilai ideal dari koefisien daya pada turbin angin tidak melebihi nilai 0.593. Di dalam penelitian ini masih termasuk ke dalam kategori yang baik, dikarenakan tidak melebihi batas Betz.
\end{abstract}

Kata Kunci : Turbin atap rumah, Putaran rendah, Jumlah sudu, Unjuk kerja

\section{PENDAHULUAN}

Menurut Outlook Energi Nasional 2011, dalam kurun waktu 2000-2009 konsumsi energi Indonesia meningkat rata-rata sebesar $2,2 \%$ pertahun. Upayaupaya pencarian sumber energi alternatif selain fosil menyemangati para peneliti di berbagai negara untuk mencari energi 
lain yang kita kenal sekarang dengan istilah energi terbarukan. Pengembangan energi angin skala besar di indonesia masih mengalami kendala karena kondisi angin yang rendah, dan cenderung berubah-rubah, permasalahan lain pemasangan turbin angin biasanya adalah masalah tempat di mana harus menyediakan sebuah tiang yang cukup kuat agar bisa menahan sudu yang besar, kebisingan, getaran di hasilkan struktur atap dan bahaya untuk burung. Lebih sedikit perhatian difokuskan pada turbin angin skala kecil yang dapat ditempatkan di atap bangunan. (Reymond E Paggi 2010).

Turbin angin yang di aplikasikan pada puncak kemiringan atap bentuk memanjang sangat jarang di aplikasikan di indonesia mengingat potensi angin kemiringan atap rumah yang tergolong kecepatan angin rendah dan cendrung ber ubah-ubah arah. Sehingga perlu dikembangkan turbin angin atap rumah yang mampu memaksimalkan angin rendah. (Watson et, 2008), melihat permasalahan tersebut tentunya pemilihan jenis turbin, bentuk airfoil, dan jumlah blade sangat menentukan prestasi turbin angin atap rumah. Selain itu pertimbangan aerodinamika bentuk airfoil yang diinginkan tentunya memiliki self starting yang tinggi sehingga mampu menghasilkan daya keluaran, daya mekanik dan coefesien daya paling optimum. turbin angin jenis savonius memiliki kemampuan selfstarting yang bagus, karena mampu memaksimalkan energi angin mendorong blade, sehingga hanya membutuhkan angin dengan kecepatan rendah untuk memutar rotor dari turbin angin ini. Selain itu, torsi yang dihasilkan blade turbin angin jenis savonius relatif tinggi (Sargolzei, 2007). Dengan pertimbangan estimasi waktu dan biaya maka, Metode penelitian ini menggunakan percobaan eksprimen motion model menggunakan
Computational Fluid Dynamic, melihat interaksi variabel faktor yang dicobakan seperti kecepatan angin, dan jumlah sudu dengan paremeter daya keluaran, daya mekanik dan coefesien daya paling optimum.

\section{METODE PENELITIAN}

Metode yang di gunakan dalam penelitian turbin angin tipe atap rumah ini adalah dengan memperhatikan dan menggunakan dari faktor desain awal desain turbin yang terdiri dari dimensi turbin $300 \mathrm{~mm}$, panjang turbin 1000 mm, jumlah blade $3,4,5$, kelengkungan blade $140^{\circ}$, jarak celah blade $20 \mathrm{~mm}$, tebal blade $2 \mathrm{~mm}$, dan material blade aluminium, selanjutnya dilakukan pemodelan turbin menggunakan sofware Pro-eng desing untuk menentukan kondisi optimum. Kemudian dilakukan simulasi dengan menggunakan CFD untuk melihat aliran kecepatan angin atau fluida udara dengan melakukan pemodelan secara 3-D dengan berbagai variasi desain yang telah di tentukan. Setelah geometri dibuat, maka langkah selanjutnya adalah melakukan simulasi dengan memasukkan input-input variabel dan parameter yang menjadi batas pada simulasi. Simulasi yang digunakan yaitu simulasi 3-D hasil yang didapat berupa tampilan geometri yang memiliki kontur dan vector kecepatan angin serta tekanan. 
p-ISSN 2502-4922,e-ISSN 2615-0867

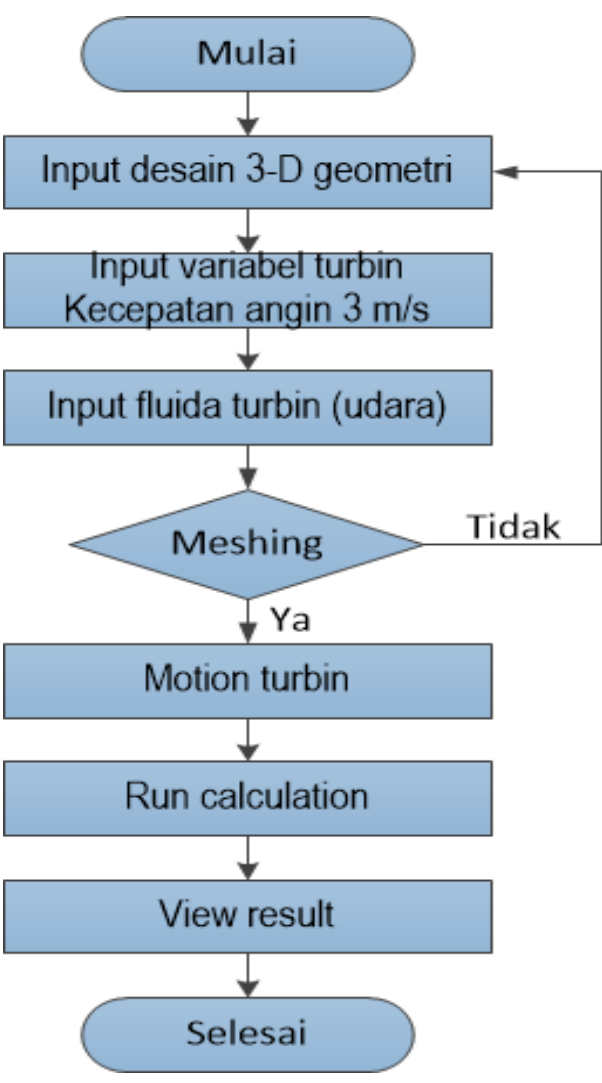

Gambar 3.5. Diagram alir simulasi

HASIL DAN PEMBAHASAN

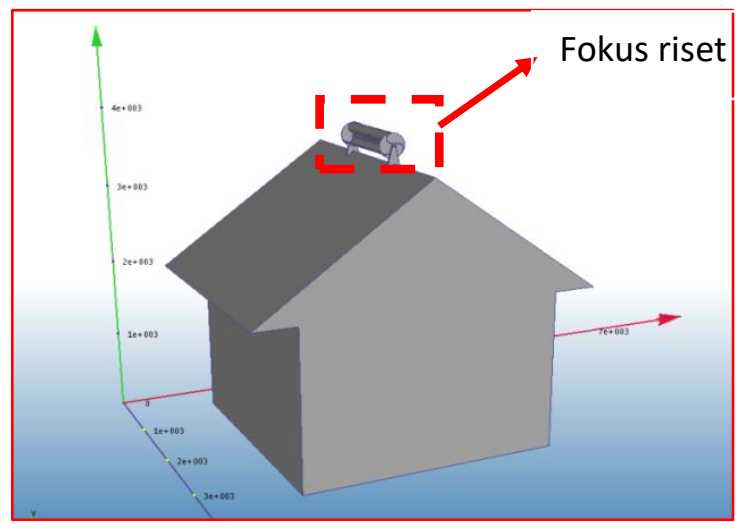

Gambar 4.1. Pemodelan turbin angin atap rumah

\section{Data kecepatan angin atap rumah}

\begin{tabular}{|l|l|l|l|l|}
\hline \multirow{3}{*}{ No } & \multicolumn{3}{|l|}{$\begin{array}{l}\text { Tgl, 15/06/17-14/07/2017 } \\
\text { Kecepatan angin v, (m/s) }\end{array}$} & $\begin{array}{l}\text { Tgl, 15/07/17- } \\
13 / 08 / 2017 \\
\text { Kecepatan angin } \\
(\mathrm{m} / \mathrm{s})\end{array}$ \\
\cline { 2 - 5 } & \multicolumn{3}{|c|}{ rata- rata harian $(\mathrm{m} / \mathrm{s})$} & $\begin{array}{l}\text { rata- rata harian } \\
(\mathrm{m} / \mathrm{s})\end{array}$ \\
\hline 1 & $2.9-6.6$ & 36.7 & $1.4-7.9$ & 30.8 \\
\hline 2 & $2.5-5.5$ & 33.5 & $0.5-6.7$ & 26.5 \\
\hline 3 & $2.1-4.7$ & 28.5 & $3.4-5.1$ & 34.8 \\
\hline 4 & $3.1-7.1$ & 39.9 & $0.5-7.1$ & 31.4 \\
\hline 5 & $3.3-7.4$ & 40.7 & $0.4-4.5$ & 21.5 \\
\hline
\end{tabular}

\begin{tabular}{|l|l|l|l|l|}
6 & $1.3-3.8$ & 25.4 & $3.0-5.3$ & 34.6 \\
\hline 7 & $1.1-4.5$ & 24.3 & $0.7-4.5$ & 21.8 \\
\hline 8 & $3.5-7.7$ & 42.1 & $1.3-5.8$ & 31.5 \\
\hline 9 & $1.3-4.5$ & 23.3 & $1.3-6.7$ & 33 \\
\hline 10 & $1.4-4.7$ & 26.8 & $1.7-7.7$ & 34.9 \\
\hline 11 & $2.3-6.9$ & 37.3 & $1.8-6.9$ & 40.3 \\
\hline 12 & $2.5-4.5$ & 29.5 & $0.5-4.5$ & 24 \\
\hline 13 & $2.1-7.2$ & 34.4 & $2.1-7.2$ & 34.8 \\
\hline 14 & $1.4-6.5$ & 33.5 & $1.7-6.5$ & 30.3 \\
\hline 15 & $1.3-5.1$ & 22.6 & $1.4-8.2$ & 29.1 \\
\hline 16 & $2.5-5.7$ & 27.8 & $1.8-4.4$ & 29.1 \\
\hline 17 & $3.6-7.9$ & 48.9 & $0.9-7.8$ & 24.7 \\
\hline 18 & $2.1-6.7$ & 35.6 & $2.7-8.5$ & 39 \\
\hline 19 & $1.7-6.9$ & 35.7 & $3.5-6.8$ & 42.2 \\
\hline 20 & $2.5-4.5$ & 29.5 & $1.5-6.8$ & 38.5 \\
\hline 21 & $1.5-5.6$ & 31.4 & $1.4-7.2$ & 30.9 \\
\hline 22 & $2.5-6.4$ & 31.3 & $3.0-6.1$ & 37.2 \\
\hline 23 & $1.8-5.9$ & 32 & $2.8-6.4$ & 38.3 \\
\hline 24 & $1.5-6.3$ & 35.5 & $2.9-6.3$ & 35.5 \\
\hline 25 & $1.7-3.9$ & 25.3 & 1.8 .5 .3 & 30.6 \\
\hline 26 & $1.2-7.8$ & 33.4 & $1.9-4.5$ & 28.7 \\
\hline 27 & $2.9-6.7$ & 31.5 & $0.7-6.7$ & 25.5 \\
\hline 28 & $1.5-7.3$ & 40 & $3.5-7.3$ & 37.8 \\
\hline 29 & $1.6-6.2$ & 34.1 & $31-5.6$ & 35 \\
\hline 30 & $1.7-5.3$ & 23 & $3.3-8.7$ & 44.9 \\
\hline & & & Rata- rata bulanan, \\
\hline & Rata- rata bulanan, 32.45 & 32.59 & \\
\hline
\end{tabular}

Dengan memperhatikan desain awal di atas, perlu diperhitungan faktor utama di dalam mendesain suatu turbin angin di atas atap rumah, yaitu kecapatan angin diasumsi konstan pada $3(\mathrm{~m} / \mathrm{s})$, faktor blade turbin angin savonius profil $\mathrm{U}(3$, 4 dan 5 blade), kelengkungan blade $140^{\circ}$, jaral celah blade $20(\mathrm{~mm})$, diameter rotor 300 (mm), panjang $1000(\mathrm{~mm})$ serta material blade yang digunakan adalah Aluminium.

\section{Perhitungan Desain Awal Turbin Atap Rumah}

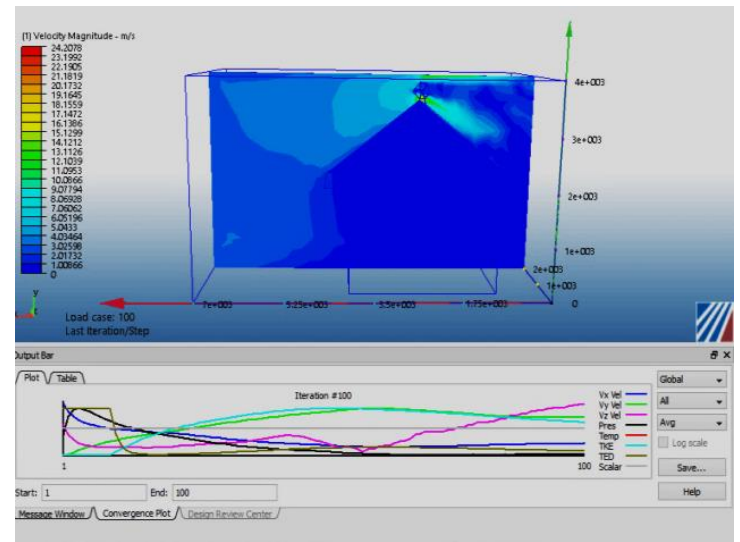


Gambar 4.4. Hasil simulasi CFD untuk 3 blade

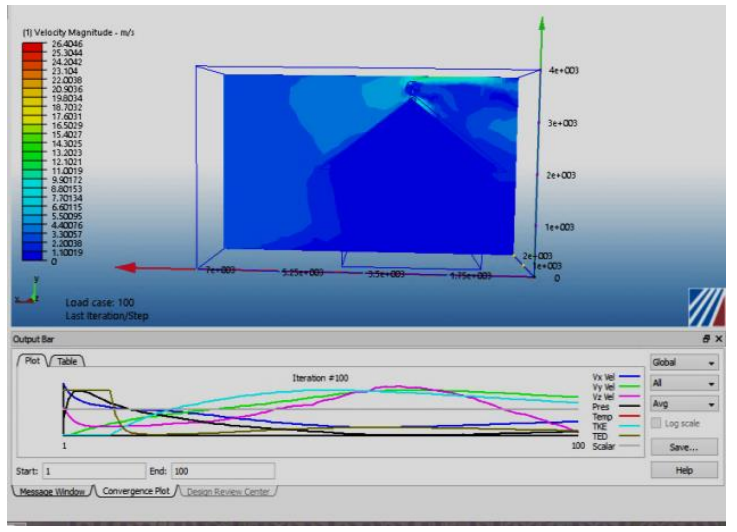

Gambar 4.5. Hasil simulasi CFD untuk 4 blade

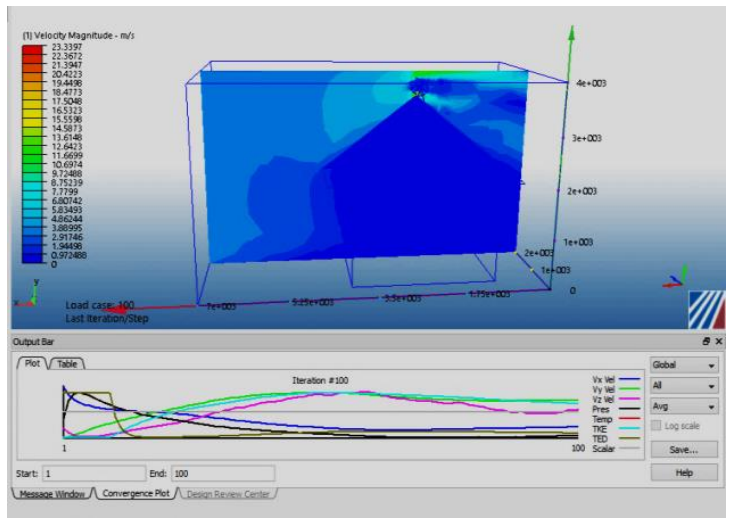

Gambar 4.5. Hasil simulasi CFD untuk 5 blade

Tabel 4.1. Data simulasi kecepatan angin turbin atap rumah

\begin{tabular}{|c|c|c|}
\hline \multirow{2}{*}{$\begin{array}{c}\text { Jumlah } \\
\text { Blade }\end{array}$} & \multicolumn{2}{|c|}{ Kecepatan angin $[\mathrm{m} / \mathrm{s}]$} \\
\cline { 2 - 3 } & Masuk rata-rata & $\begin{array}{c}\text { Keluar rata- } \\
\text { rata }\end{array}$ \\
\hline 3 & 3.66 & 1.47 \\
\hline 4 & 3.36 & 1.51 \\
\hline 5 & 3.48 & 1.62 \\
\hline
\end{tabular}

\section{Perhitungan $\boldsymbol{P}_{W}(\mathrm{~W})$}

Dengan menggunakan data pada Tabel 4.1. dapat dilakukan perhitungan daya teorittis $\left(P_{w}\right)$ dan daya mekanik turbin hasil simulasi $\left(P_{T}\right)$ serta koefisien daya turbin $(\mathrm{Cp})$ dengan menggunakan persamaan berikut :

$$
P_{w}=\frac{1}{2}(\rho A v)\left(v^{2}\right)=\frac{1}{2} \rho A v^{3}
$$

Tabel 4.2. Data perhitungan daya angin $P_{W}(\mathrm{~W})$

\begin{tabular}{|c|c|}
\hline Jumlah Blade & Daya angin $[\mathrm{W}]$ \\
\hline 3 & 49.6125 \\
\hline 4 & 49.6125 \\
\hline 5 & 49.6125 \\
\hline
\end{tabular}

\section{Perhitungan $\boldsymbol{P}_{T}(\mathrm{~W})$}

Untuk menghitung daya mekanik turbin angin dapat menggunakan persamaan berikut ini :

$$
P_{T}=\frac{1}{4} \rho A\left(v_{1}+v_{2}\right)\left(v_{1}^{2}-v_{2}^{2}\right)
$$

Tabel 4.3. Data daya mekanik turbin $P_{T}$ (W)

\begin{tabular}{|c|c|}
\hline Jumlah blade & $\begin{array}{c}\text { Daya mekanik turbin } \\
{[\mathrm{W}]}\end{array}$ \\
\hline 3 & 27.86593 \\
\hline 4 & 27.96002 \\
\hline 5 & 28.65473 \\
\hline
\end{tabular}

\section{Perhitungan Cp (\%)}

Selanjutnya menentukan koefisien daya $(\mathrm{Cp})$ turbin angin Savonius profil $\mathrm{U}$, perhitungan dilakukan dengan menggunakan persaman di bawah ini :

$$
C p=\frac{P_{T}}{P_{W}}=\frac{\frac{1}{4} \rho A\left(v_{1}+v_{2}\right)\left(v_{1}^{2}-v_{2}^{2}\right)}{\frac{1}{2} \rho A v_{1}^{3}}
$$

Tabel 4.4. Data koefisien daya (Cp) turbin angin

\begin{tabular}{|c|l|l|c|}
\hline $\begin{array}{c}\text { Jumlah } \\
\text { blade }\end{array}$ & $\begin{array}{l}\text { Daya } \\
\text { teoritik }\left(P_{w}\right)\end{array}$ & $\begin{array}{l}\text { Daya } \\
\text { mekanik }\left(P_{T}\right)\end{array}$ & $\mathrm{Cp}$ \\
\hline 3 & 49.6125 & 27.86593 & 0.561 \\
\hline 4 & 49.6125 & 27.96002 & 0.563 \\
\hline 5 & 49.6125 & 28.65473 & 0.577 \\
\hline
\end{tabular}




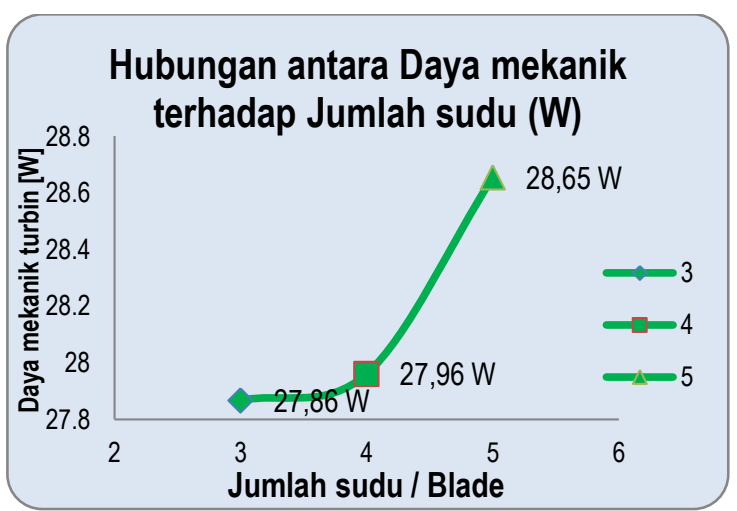

Gambar 4.7. Hubungan $P_{T}$ terhadap Jumlah Blade

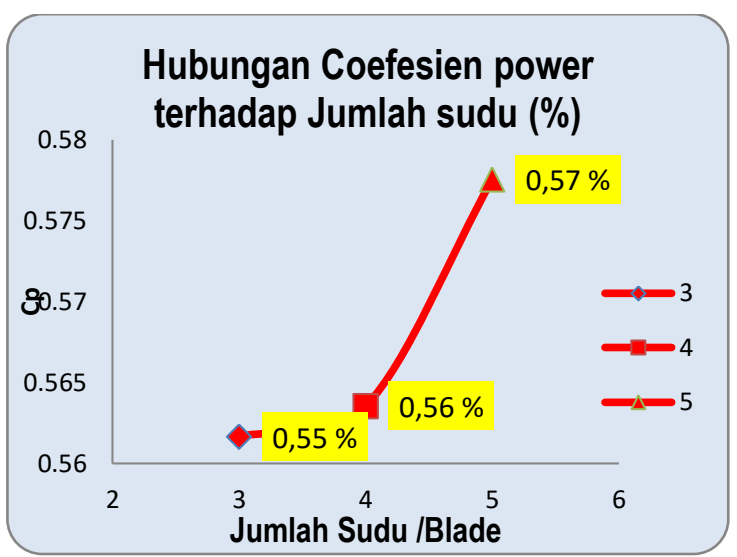

Gambar 4.8. Hubungan Cp terhadap Jumlah Blade

Berdasarkan gambar grafik 4.7 4.8. memberikan perbandingan antara $\mathrm{P}_{\mathrm{T}}$ dan $\mathrm{Cp}$ terhadap jumlah blade di turbin angin. Pada gambar grafik 4.7 diatas menerangkan bahwa jumlah blade memiliki andil kenaikan daya mekanik turbin $\left(\mathrm{P}_{\mathrm{T}}\right)$. Jika menggunakan blade sebanyak 3 buah maka akan memperoleh $\left(\mathrm{P}_{\mathrm{T}}\right)$. sebesar 27,85 W, begitu pula untuk blade yang berjumlah 4 akan didapatkan $\left(\mathrm{P}_{\mathrm{T}}\right)$ sebesar 27,96 W. Dan terus meningkat pada jumlah blade 5 buah yaitu $\left(\mathrm{P}_{\mathrm{T}}\right)$ yang di di capai sebesar 28,65 W. Hal ini membuktikan bahwa jumlah blade berperan untuk menaikkan besaran daya keluaran $\left(\mathrm{P}_{\mathrm{T}}\right)$. yang dihasilkan turbin angin atap rumah.

Sedangkan untuk gambar grafik 4.8 menjelaskan pola yang hampir sama dengan Gambar 4.7 sebelumnya, bahwa besaran nilai coefesien daya $\mathrm{Cp}$, akan mengalami kenaikan apabila menggunakan jumlah blade yang besar pula. Dimana blade sebanyak 3 buah mampu menghasilkan coefesien daya $\mathrm{Cp}$, sebesar $55,1 \%$, begitu pula untuk blade yang berjumlah 4 akan didapatkan coefesien daya $\mathrm{Cp}$, sebesar 56,3\% . Dan terus meningkat pada jumlah blade 5 buah yaitu coefesien daya $\mathrm{Cp}$, yang dihasilkan sebesar 57,8\%. Hal ini juga membuktikan bahwa jumlah blade berperan untuk menaikkan besaran coefesien daya $\mathrm{Cp}$, yang dihasilkan turbin angin atap rumah.

\section{KESIMPULAN}

Berdasarkan analisis turbin angin atap rumah dalam penelitian ini dapat disimpulkan beberapa hal sebagai berikut :

1. Turbin atap rumah blade 5 buah memiliki pengaruh paling besar terhadap daya mekanik sebesar $28.185 \mathrm{~W}$, dan koefisien daya $\mathrm{Cp}$, sebesar $0.58 \%$. Selanjutnya tertinggi kedua di hasilkan turbin atap rumah blade 4 buah memiliki pengaruh terhadap daya mekanik sebesar 27.96 $\mathrm{W}$, dan koefisien daya $\mathrm{Cp}$, sebesar $0.56 \%$. Sedangkan turbin atap rumah blade 3 buah memiliki pengaruh paling besar ketiga terhadap daya mekanik sebesar $27.86 \mathrm{~W}$, dan koefisien daya $\mathrm{Cp}$, sebesar $0.55 \%$.

2. Dimensi model turbin angin atap rumah yang paling optimal dari ketiga model hasil simulasi desain dan perhitungan yaitu hasil simulasi desain no 3. Turbin angin atap rumah jumlah blade 5 buah menghasilkan daya turbin maksimum sebesar, $28.185 \mathrm{~W}$, dan koefisien daya $\mathrm{Cp}$, sebesar $0.568 \%$. Menurut Betz limit, bahwa nilai ideal dari koefisien daya pada turbin angin tidak melebihi nilai 0.593. Di dalam penelitian ini masih termasuk ke dalam kategori yang baik, dikarenakan tidak melebihi batas Betz. 


\section{REFERENSI}

[1] Raymond E. Paggi, 2010. Paten Application Ser. No. 61/105,096, filed Nov.24, 2008, Entidled Roof Ridge Wind Turbine.

[2] Rosidin, Nanang. 2007. Perancangan, Pembuatan, dan Pengujian Prototipe SKEA Menggunakan Rotor Savonius dan Windside Untuk Penerangan Jalan Tol. Bandung: ITB.

[3] Andreas Andi Setiawan, dkk. 2014. Pengaruh Jarak Celah Sudu Terhadap Unjuk Kerja Turbin. Angin Poros Vertikal Savonius.

[4] Andry kusbiantoro, Rudy soenoko dan Djoko sutikno 2009. Pengaruh panjang lengkung sudu terhadap unjuk kerja turbin angin poros vertikal savonius.

[5] Daryanto, Y, 2007. Kajian Potensi Angin Untuk Pembangkit Listrik Tenaga Bayu. Balai PPTAGG UPT-LAGG.

[6] Watson et, 2008, Estimating The Potential Yield of Small Building Monted Wind Turbines.

[7] Lubitz. 2008. Effec Roof Slope on a Building Monted Wind Turbine.

[8] David Wood, 2011. Small Wind Turbines, Analisys, Design, and Application.

[9] Dutton, A., Halliday, J., \& Blanch, M. 2005. The Feasibility of BuildingMounted/Integrated Wind Turbines (BUWTs): Achieving their Potential for Carbon Emission Reductions. Energy Research Unit, CCLRC. 